Review

\title{
Zeolite-based Materials for Gas Sensors
}

\author{
Xiaowen $\mathrm{Xu}{ }^{1,2, *}$, Jing Wang ${ }^{1, \ddagger}$ and Yingcai Long ${ }^{1, *}$
}

${ }^{1}$ Shanghai Key Laboratory of Molecular Catalysis and Innovative Materials, Department of Chemistry, Fudan University, Shanghai 200433, P.R. China; $\ddagger$ E-mail: jing-wang@fudan.edu.cn

2 Department of Chemistry, University of Science and Technology of Suzhou, Suzhou 215011, P.R. China

* Authors to whom correspondence may be addressed; Tel: (+86)-21-6564-3913; Fax: (+86)-21-65641740, E-mail: yclong@fudan.edu.cn (Y-C. Long); xwxu@mail.usts.edu.cn (X. Xu)

Received: 29 September 2006; in revised form: 1 November 2006 / Accepted: 13 December 206 / Published: 13 December 2006

\begin{abstract}
This review of 53 references deals with the uses of zeolites and zeolite-based materials for developing gas sensors. The potential of these materials is highlighted and avenues for further research are suggested.
\end{abstract}

Keywords: Zeolite; gas sensing; guest/host materials; absorption.

\section{Introduction}

Zeolites are composed of a framework of tetrahedral $\mathrm{TO}_{4}$ building units ( $\mathrm{T}=\mathrm{Si}$, $\mathrm{Al}$, etc.). The tetrahedral $\mathrm{TO}_{4}$ units link with each other by sharing oxygen atoms to form three-dimensional crystalline porous skeletons. The T-O-T links result in a variety of rings, which are responsible for zeolites' cages and channels of different window sizes. Within the framework structure, the $\mathrm{A} 1^{3+}$ atom at the center of an $\mathrm{AlO}_{4}$ tetrahedron connects to a neighboring $\mathrm{SiO}_{4}$ tetrahedron by sharing an $\mathrm{O}$ atom, and thus generates a negative framework charge which is balanced by an exchangeable cation, such as an alkaline or alkaline-earth cation and thus, the property of ion exchange is provided [1]. By means of ion-exchange with different cations, the pore size, the ion conductivity, the adsorption and catalytic selectivity of zeolites can obviously be modified.

The pores and the cages with certain window sizes within a zeolite's framework allow some molecules to pass through and others to be excluded, and result in a molecular sieve effect (Figure 1). Zeolites usually possess three, two or one dimensional channel systems, and the window sizes are in 
the 0.3-1.5 nm range. For example, FAU type zeolite has three dimensional $0.74 \mathrm{~nm}$ channels with 12 oxygen ring windows and supercages of 1-2 $\mathrm{nm}$ of diameter (Figure 2), FER zeolite has two dimensional channels, 10 oxygen ring channels with $0.54 \mathrm{~nm} \times 0.42 \mathrm{~nm}$ windows and 8 oxygen ring channels with $3.5 \mathrm{~nm} \times 4.8 \mathrm{~nm}$ openings (Figure 3) [2].

Figure 1. Schematic representation of several typical zeolite windows and the molecular sieve effect.

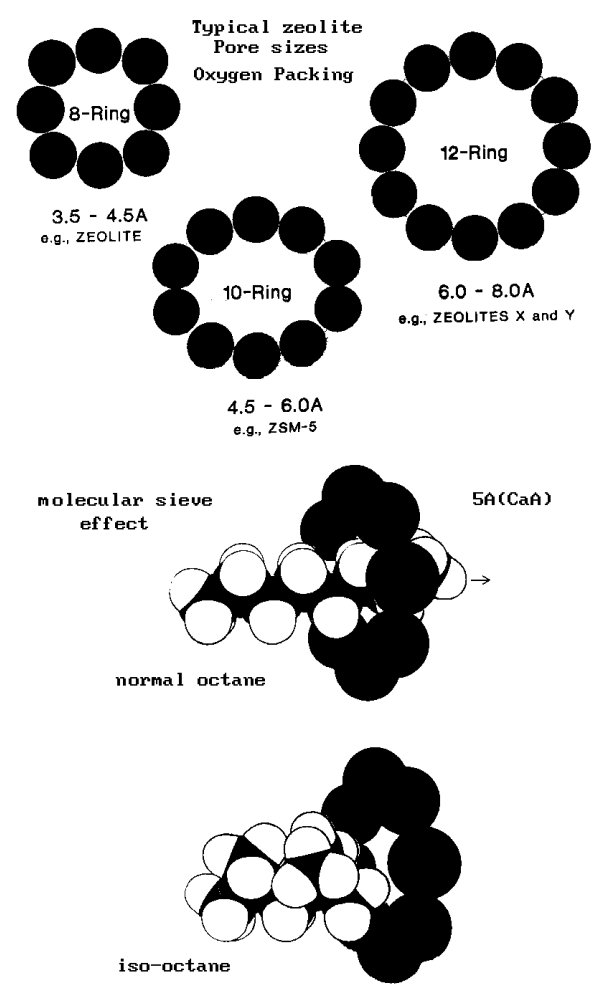

Figure 2. The FAU type zeolite supercage (viewed along [111]).

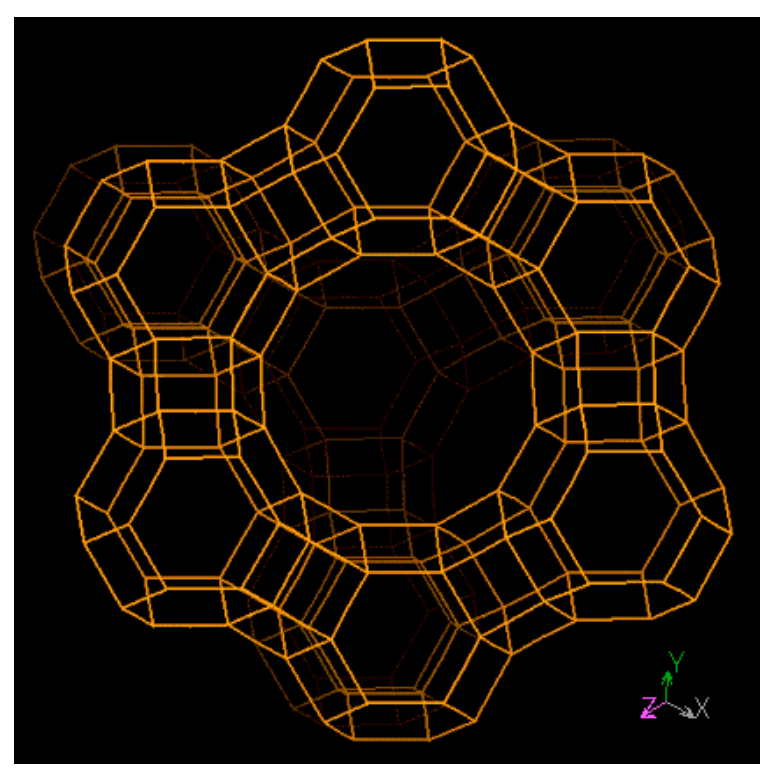


Figure 3. The FER type zeolite framework (viewed along [001] and [010]).

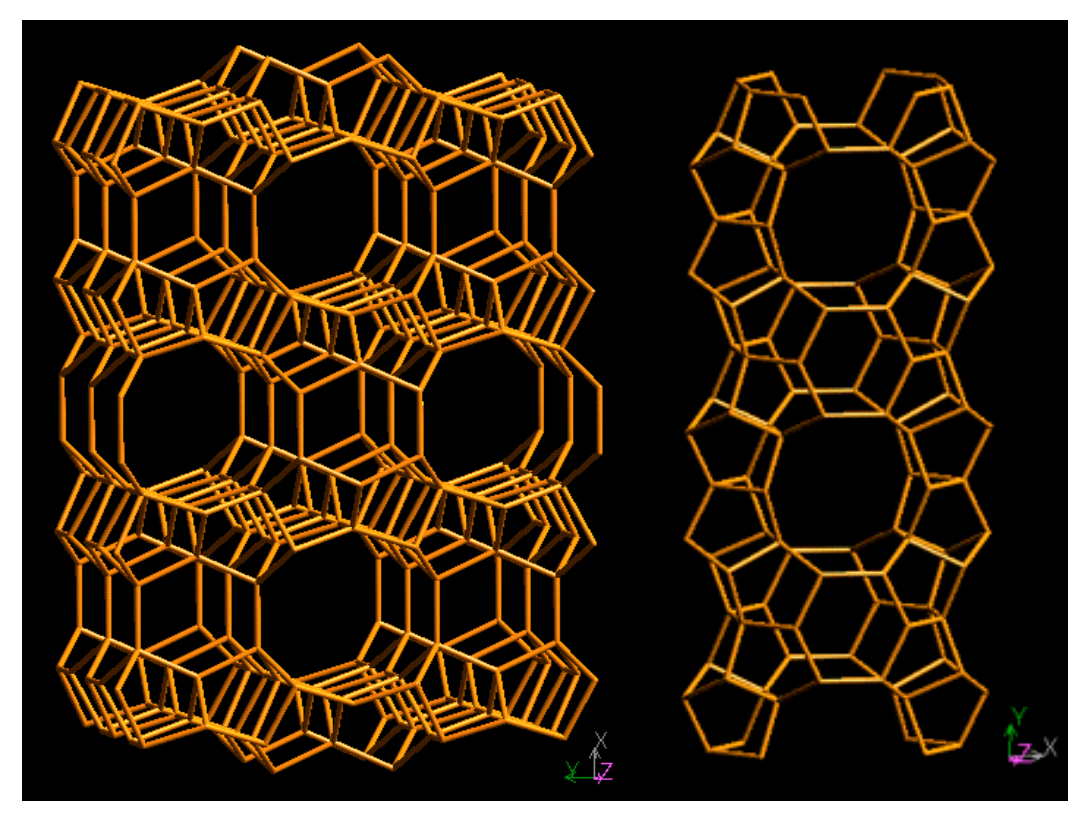

The Si/Al ratio in a zeolite's framework can usually be effectively adjusted, and by changing the framework $\mathrm{Si} / \mathrm{Al}$ ratio of the zeolite, the ion-exchange capacity and conductivity, the interaction between the zeolite and the adsorbed molecules, and the modification of hydrophilic or hydrophobic properties can all be changed. The zeolites with low silica contents are hydrophilic, and are usually used as drying agents for absorbing steam, whereas hydrophobic high siliceous zeolites are used for absorbing organic molecules from humid air or water. In principle, varying the framework Si/Al ratio of zeolites greatly changes the adsorption selectivity towards molecules with different polarity.

With their excellent chemical and thermal stability, zeolites can be used as a substrate to prepare compounds and devices with desirable fundamental physical and chemical properties. For example, inorganic or organic compounds, metal and metal-organic compounds and their clusters can be assembled into the pores and the cages in zeolites. Some nano-sized metal or metal oxide particles have been successfully inserted into the caves and the pores or highly dispersed on the external surface of zeolites.

Some applications of zeolite materials in gas sensors have been developed based on the characteristics mentioned above: 1) Assembly of a compound specifically sensing a gas into zeolite cages or channels, for example, encapsulating ruthenium (II) complexes inside zeolite supercages as an oxygen sensor, inserting methylene blue into zeolites for optical humidity sensing or assembling $\mathrm{LiCl}$ into zeolites as humidity sensors; 2) Fixing of zeolites on quartz crystal microbalances (surfaceacoustic-wave, microcantilever, or optical fiber) for sensing some gases by selective absorption; 3 ) Changing the conductivity of zeolites due to the absorbance of some gases for making sensors based on impedance spectroscopy measurements; 4) Placing zeolites onto sensors as filter materials for enhancing the selectivity to a certain gaseous molecule; 5) Immersing zeolites into some materials or supports forming composites for making sensors, such as the conductivity of polyaniline/zeolite composites responsive to $\mathrm{CO}, \mathrm{SnO}_{2}$ /zeolite composites responsive to $\mathrm{H}_{2}$ and $\mathrm{CO}$ (Table 1). 
Table 1. Types of zeolite-based materials for gas sensors.

\begin{tabular}{|c|c|c|c|c|}
\hline Type & Materials & $\begin{array}{c}\text { Function of } \\
\text { zeolite } \\
\end{array}$ & Sensed gas & Literature \\
\hline Guest/host & $\begin{array}{l}\text { Ru(II) complex/zeolite } \\
\text { methylene blue/zeolite } \\
\text { LiCl/zeolites }\end{array}$ & Supported & $\begin{array}{c}\mathrm{O}_{2} \\
\mathrm{H}_{2} \mathrm{O} \\
\mathrm{H}_{2} \mathrm{O}\end{array}$ & $\begin{array}{c}{[6,7,8]} \\
{[51]} \\
{[46-50]}\end{array}$ \\
\hline $\begin{array}{l}\text { Change of } \\
\text { mass }\end{array}$ & $\begin{array}{l}\text { zeolites/quartz crystal } \\
\text { microbalance } \\
\text { zeolites/surface-acoustic- } \\
\text { wave } \\
\text { zeolite / microcantilever } \\
\text { zeolite/cantilever }\end{array}$ & Adsorbed & $\begin{array}{c}\mathrm{NO}, \mathrm{SO}_{2} \\
\mathrm{SO}_{2} \\
\text { dimethylmethylphosphonate } \\
\text { acetone } \\
\text { pentane, hexane and } \mathrm{H}_{2} \mathrm{O} \\
\mathrm{H}_{2} \mathrm{O} \\
\mathrm{NH}_{3} \\
\\
\text { freon } \\
\mathrm{H}_{2} \mathrm{O} \\
\end{array}$ & $\begin{array}{c}{[22]} \\
{[23]} \\
{[26]} \\
{[27]} \\
{[28]} \\
{[52]} \\
{[21]} \\
\\
{[29,30]} \\
{[53]} \\
\end{array}$ \\
\hline Conductive & $\begin{array}{l}\text { proton conductive zeolites } \\
\mathrm{Na}^{+} \text {ion conducting ZSM-5 } \\
\text { zeolite } \\
\text { conductive }\end{array}$ & Adsorbed & $\begin{array}{c}\mathrm{NH}_{3} \\
\text { hydrocarbons } \\
\text { methanol, 2-propanol and 3- } \\
\text { pentanol }\end{array}$ & $\begin{array}{c}\text { [16-19] } \\
{[34]} \\
{[40]}\end{array}$ \\
\hline $\begin{array}{l}\text { Film of filter } \\
\text { or absorbed }\end{array}$ & $\begin{array}{l}\text { zeolite film/sensors } \\
\text { faujasite/metglas } \\
\text { zeolite/optical fiber } \\
\text { zeolite/a surface plasmon } \\
\text { resonance sensor }\end{array}$ & Adsorbed & $\begin{array}{c}\mathrm{O}_{2} \\
\mathrm{CO}_{2} \\
\mathrm{CO} \\
\mathrm{CO}_{2} \\
\text { organics } \\
\text { butylamine } \\
\end{array}$ & $\begin{array}{c}{[9,10]} \\
{[11]} \\
{[13]} \\
{[12]} \\
{[31-33]} \\
{[20]} \\
\end{array}$ \\
\hline Composites & $\begin{array}{l}\text { polyaniline/zeolite } \\
\text { yttria stabilized } \\
\text { zirconia/zeolite } \\
\text { platinum/Y-zeolites } \\
\mathrm{SrTi}_{1-\mathrm{x}} \mathrm{Fe}_{\mathrm{x}} \mathrm{O}_{3} / \text { zeolite } \\
\text { chromium titanium } \\
\text { oxide/zeolite } \\
\mathrm{TiO}_{2} / \text { zeolite } \\
\mathrm{SnO}_{2} / \text { zeolite }\end{array}$ & Supported & $\begin{array}{c}\mathrm{CO} \\
\mathrm{NO} \\
\mathrm{C}_{4} \mathrm{H}_{10}, \mathrm{CO} \text { and } \mathrm{H}_{2} \\
\text { hydrocarbons } \\
\text { alkanes } \\
\text { hydrocarbons } \\
\mathrm{H}_{2} \text {, CO } \\
\text { methane, propane, and ethanol } \\
\mathrm{H}_{2}, \mathrm{CO}\end{array}$ & $\begin{array}{c}{[14,15]} \\
{[24,25]} \\
{[35]} \\
{[36]} \\
\\
{[37]} \\
{[38]} \\
{[45]} \\
{[39]} \\
{[41-44]}\end{array}$ \\
\hline
\end{tabular}

The applications of zeolite materials have been reviewed previously [3-5], but there have been no reports covering the uses of zeolite-based materials for gas sensors. This review would fill a gap by 
summarizing the applications of zeolite materials in some important gas sensor uses in recent years, and call scientist's and engineer's attention to the great potential of these materials.

\section{Sensors}

\section{1. $\mathrm{O}_{2}$ sensors}

Sensors for detecting and measuring oxygen in gaseous phase or in solution are very important in the field of chemical sensors and biosensors. The zeolite-based materials used for this purpose include the ruthenium (II) bipyridyl complex $\left(\mathrm{Ru}^{2+}(\mathrm{bpy})_{3}\right)$, which was prepared inside the supercages of a FAU type zeolite, and is an excellent fluorescent oxygen probe. The prepared sensor materials were tested with respect to the quenching of luminescence intensity by molecular oxygen, resulting in measurable responses oxygen. The materials have long-term stability under various conditions with a measuring range of 0-760 Torr, among which the $0 \sim 200$ Torr region presents very good resolution. Both the quenching efficiency and the long-term stability of the Stern-Volmer quenching constant are tremendously improved in comparison with other sensors where the fluorophore is absorbed onto the surface of either a zeolite or silica gel [6]. The highly siliceous zeolitic framework leads to a hydrophobic environment and promotes oxygen transfer from water to the zeolite. The $\left[\mathrm{Ru}(\mathrm{bpy})_{3}\right]^{2+} /$ highly siliceous FAU zeolite material is a good candidate for use as a dissolved oxygen sensor $[7,8]$.

A continuous zeolite film covering the entire sensor surface was designed and prepared on the surface of oxygen sensors, which selectively limits gas exposure on the sensing surface or enriches oxygen. The oxygen is pre-adsorbed/entrapped on/into the zeolite. The results proved that the desirable levels of "oxygen-enhancement" had been achieved, and the measurement precision for oxygen containing gases had been improved in these sensors $[9,10]$.

\section{2. $\mathrm{CO}$ and $\mathrm{CO}_{2}$ sensors}

A practical $\mathrm{CO}_{2}$ gas sensor for air quality control has been developed by using a zeolite as a filter material combined with a solid electrolyte of $\mathrm{Na}_{3} \mathrm{Zr}_{2} \mathrm{Si}_{2} \mathrm{PO}_{12}$ (NASICON) and $\mathrm{Li}_{2} \mathrm{CO}_{3}$. The electromotive force of the sensor shows a linear relationship with the logarithm of $\mathrm{CO}_{2}$ concentration. The sensor with zeolite as a filter material minimizes the effect of interfering gases on the sensor's electromotive force, and shows very little deterioration of its response to $\mathrm{CO}_{2}$ [11]. A composite material of FAU type zeolite-Metglas can be used in gas-sensing applications, in which a continuous film of FAU zeolite was synthesized on a Metglas magnetoelastic strip using a secondary growth method. The sensor made of composite presents the ability to remotely sense carbon dioxide in a nitrogen atmosphere at room temperature over a wide range of concentrations by monitoring the changes of the resonance frequency on the strip. The zeolite-Metglas composite can also be used as a sensor for a specific gas analyte in a mixture on the condition that the composite possess much higher selectivity of adsorption towards that gas than other components in the mixture [12]. Siliceous FER type zeolites, possessing a prominent ethanol-filtering effect, was coated on a sensing layer of $\mathrm{La}_{2} \mathrm{O}_{3}{ }^{-}$ $\mathrm{Au} / \mathrm{SnO}_{2}$ ceramics for reducing the $\mathrm{C}_{2} \mathrm{H}_{5} \mathrm{OH}$ interference. The sensor based on the ceramic coated with 
the zeolite presents high selectivity towards $\mathrm{CO}$ among $\mathrm{H}_{2}, \mathrm{CH}_{4}, \mathrm{i}-\mathrm{C}_{4} \mathrm{H}_{10}, \mathrm{C}_{2} \mathrm{H}_{4}$, and $\mathrm{C}_{2} \mathrm{H}_{5} \mathrm{OH}$. As a result, a $\mathrm{CO}$ selective gas sensor was obtained, which has a sensitivity towards $\mathrm{CO}$ over ten times higher than that towards other gases at about 573K [13].

A composite polyaniline/zeolite material can also be used as a CO sensor [14]. The material exhibits an electrical conductivity response to $\mathrm{CO}$, which is related to the content, pore size and ion

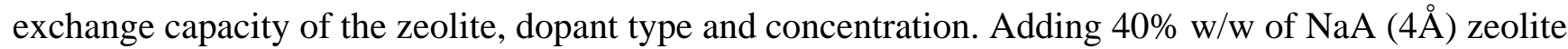
reduces the electrical conductivity response, but improves the sensitivity towards CO. This concentration is evidently below the percolation threshold value, which is estimated to be above $50 \%$ w/w. The composite with KA ( $3 \AA$ ) zeolite has a comparable sensitivity value relative to that of pure polyaniline. The composites of both zeolites have greater sensitivity values compared to that of the

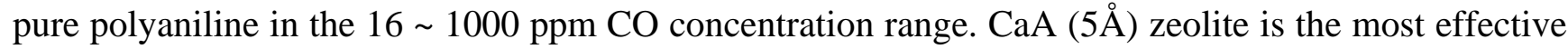
porous material in promoting the interaction between $\mathrm{CO}$ and polyaniline because that zeolite possesses the largest pore size in LTA type zeolite compared with KA and NaA [15].

\section{3. $\mathrm{NH}_{3}$ and amine sensors}

Ammonia gas sensors using proton conductive zeolites and measuring impedance spectroscopy have been developed [16-19]. $\mathrm{NH}_{3}$ promotes the conduction of a proton in $\mathrm{H}$ form in zeolites and increases the specific conductivity proportional to the $\mathrm{NH}_{3}$ concentration, at the same time that it decreases the corresponding activation energy. In order to extend the use of proton conductive zeolites in gas sensing applications, the effects of methylamine and dimethylamine on the proton conductivity were studied in H-ZSM-5 $\left(\mathrm{SiO}_{2} / \mathrm{Al}_{2} \mathrm{O}_{3}=50\right)$ by measuring impedance spectroscopy [16]. A surface plasmon resonance (SPR) sensor with a thin film of LTA type zeolite on a gold surface was prepared via the thiol-alkoxysilane interfacial layers, and investigated by detecting butylamine as a malodorous substance. The anchored zeolite layer was exposed to butylamine, and the shifts of the incident angle (Delta theta) were observed. The Delta theta increased linearly with the gas concentration in the $0 \%$ $1 \%$ region [20]. The sensitivity depended on the type of zeolites in the order of $13 \mathrm{X}$ zeolite $>5 \AA$ zeolite $\approx$ mordenite $>$ ZSM-5. A zeolite-containing coating on a surface-acoustic-wave (SAW) sensor was also developed for detecting ammonia. The frequency of the SAW sensor increases in the reaction of ammonia in a humid atmosphere with the zeolite-containing coating. In ambient air with humidity higher than $10 \%$, a selective determination of ammonia was provided at a level of tenths of a percent [21].

\section{4. $\mathrm{NO}$ and $\mathrm{SO}_{2}$ sensors}

Different types of zeolites, such as zeolite A or silicalite-1 were deposited on one arm of a quartz crystal microbalance (QCM) oscillator, and another arm without deposited zeolites was used as the reference. The balance was exposed to a single gas such as $\mathrm{NO}, \mathrm{SO}_{2}$ and $\mathrm{H}_{2} \mathrm{O}$ mixed with $\mathrm{He}$ at $443 \mathrm{~K}$. The frequency shifts and their differential values vs time were measured. Both the shifts and the values were tested to elucidate which was more useful to quantify, and which of these single gases could be used as principal component. Based on these results, mixtures of $\mathrm{NO}$ and $\mathrm{SO}_{2}$ gases in $\mathrm{He}$ of various compositions were examined. The results suggested that the sensor system with the differential values, 
which represent sorption-kinetics instead of the frequency shifts representing sorption-equilibria, overcame the disadvantages of the conventional QCM sensors and showed favorable qualification and quantification performances for the gas mixtures [22]. A thin layer of FAU type zeolite was synthesized on the QCM with an $\mathrm{Au}$ electrode, and applied as a $\mathrm{SO}_{2}$ gas sensor. When $\mathrm{SO}_{2}$ gas molecules are adsorbed on the zeolite layer, the mass increase reduces the frequency of the QCM. The frequency shift of the QCM is proportional to the amount of $\mathrm{SO}_{2}$ adsorbed, resulting in a use for measuring the gas-phase concentration [23]. The NO sensor is based on a potential response to the gas, which is exposed on an electrochemically active interface of yttria stabilized zirconia with a zeolite (YSZ). The zeolite plays the role of promoting the $\mathrm{NO} / \mathrm{NO}_{2}$ equilibrium prior to the gases reaching the interface $[24,25]$. The mixed potential generated is logarithmically related to NO in the concentration range of $0 \sim 1000 \mathrm{ppm}$ at $773 \sim 973 \mathrm{~K}$. The microporosity of the zeolite makes it permeable to oxygen, thus minimizing the interference of this species.

\subsection{Hydrocarbon and organic molecule sensors}

A quartz crystal microbalance with immobilized ZSM-5 zeolite films has been developed as a sensor for the nerve agent simulant dimethylmethylphosphonate (DMMP) [26]. Frequency shifts related with different concentrations of DMMP were measured. The ambient frequency shift vs time was examined with 1 ppm, 5 ppm and 20 ppm of DMMP, respectively. A minimum detectable concentration of $1 \mathrm{ppm}$ DMMP has been obtained in $\mathrm{N}_{2}$ at $293 \mathrm{~K}$. In order to improve the selectivity of the sensor towards DMMP in the presence of other organic gases, zeolite films with different pore size such as MFI type zeolite and $\mathrm{Ag}^{+}$-modified ZSM-5 zeolite were studied. A frequency shift of the films in response to acetone and ethanol at a concentration of $1 \mathrm{ppm}$ were observed. An application of the quartz crystal microbalance modified with $\mathrm{Ag}^{+}-\mathrm{ZSM}-5$ zeolite for detecting acetone in nitrogen was developed [27]. The concentration of acetone in diabetics' breath can be measured. The minimum detectable concentration of acetone vapor was $1.2 \mathrm{ppm}$, and a lower detection limit lower than 0.26 ppm has been identified in the application for the diagnosis of diabetes. Piezoelectric sensor devices (QCM) with < $100 \mathrm{~nm}$ of LTA and BEA type colloidal zeolites were used as micro-sensors for water and organic compounds [28]. The importance of the zeolite's structure type with respect to the sensitivity towards different organic and water vapors at various concentrations was discussed. In comparison to LTA, the BEA type zeolite film shows a higher sorption capacity towards water vapor and no rejection of pentane, hexane and cyclohexane, due to the larger pore size of the zeolite. A piezoelectric micro-cantilever coated with MFI type zeolite has been developed as a freon gas sensor $[29,30]$. Excited by AC voltage, the micro-cantilever was employed to detect the concentration of freon-12 gas in the range of $0 \sim 100$ ppm by the modifying effect of the zeolite. High selectivity and sensitivity, combined with excellent repeatable and reversible performances have been exhibited with a linear relationship between the frequency shift in percent and the concentration of freon gas. The minimum mass change of $3.5 \times 10^{-9} \mathrm{~g}$ and the sensitivity of $-0.0024 \% / \mathrm{ppm}$ were determined [29].

Optical fiber sensors coated with zeolite have been developed for in situ detection of organics [31, 32]. The sensors operate by monitoring the changes of optical reflectivity caused by the selective adsorption in the zeolite pores of organic molecules, i.e., 2-propanol or pentanoic acid, from aqueous solutions. Reversible and monotonic sensor signals were observed with fast responses to the variation 
of 2-propanol concentration in water. However, the sensor responding to pentanoic acid is much slower than that for 2-propanol. Substitution of $\mathrm{Si}$ by $\mathrm{Al}$ in the MFI framework increased the adsorption of pentanoic acid, resulting in an enhancement of the sensor response [33]. A thin film of polycrystalline silicalite grown on the cleaved end face of a standard single-mode optical fiber has been successfully demonstrated for measuring the concentration of isopropanol vapor in mixtures with nitrogen [32]. ATR (attenuated total reflection) elements coated with silicalite-1 zeolite have been fabricated as a sensor for n-hexane. The zeolite film micropores enrich the analyte on the probe surface, and increase the sensitivity. At $6 \times 10^{-5}$ of the relative pressure for n-hexane in helium, the sensitivity of the probe for the zeolite coated element is approximately 85 times higher than that of a $10 \mathrm{~cm}$ transmission gas cell, and ca. 180 times higher than that for an uncoated element. The performance of the probe is illustrated by the adsorption isotherm of n-hexane on the zeolite [31].

A $\mathrm{Na}^{+}$ion conducting ZSM-5 zeolite was applied as the sensitive phase in a potentiometric gas sensor consisting of the $\mathrm{Au} /\left(\mathrm{Na}_{2} \mathrm{CO}_{3}, \mathrm{BaCO}_{3}\right)$ /zeolite/Au cell, where the $\mathrm{Na}_{2} \mathrm{CO}_{3} / \mathrm{Au}$ system serves as the reference electrode. The cell voltage showed a linear response to the changes of the logarithm of propane partial pressure (200-4000 $\mathrm{Pa}$ ) in $\mathrm{CO}_{2} / \mathrm{O}_{2} / \mathrm{N}_{2}$ at $673 \mathrm{~K}$. A mechanism was proposed based on the changes of $\mathrm{Na}$ or $\mathrm{Na}^{+}$activity in the zeolite pores due to hydrocarbon sorption. An independent effect is a weak response of the zeolite/Au electrode to $\mathrm{O}_{2}$ and $\mathrm{CO}_{2}$ due to the formation of oxide and carbonate [34]. The FAU type zeolite doped with platinum by ion-exchange has been used as a gassensitive layer material on a thin-film inter-digital capacitors (IDCs). The sensitivity of the zeolite-IDC sensor excited with AC voltage has been determined on the impedance response for $\mathrm{C}_{4} \mathrm{H}_{10}$, $\mathrm{CO}$ and $\mathrm{H}_{2}$ in wet air [35].

A P-type semiconductor family of $\mathrm{SrTi}_{1-\mathrm{x}} \mathrm{Fe}_{\mathrm{x}} \mathrm{O}_{3}$-delta with a perovskite structure has been used as the base material for a hydrocarbon sensor. A cover layer made of platinum-doped zeolite with catalytica activity has been proven to have an effect for reducing the cross-interference influence of some species. An initial model for explaining the sensing mechanism was proposed [36]. In order to improve the selectivity of metal oxide sensors, zeolites modified with chromium were used to control the selectivity to alkanes based on shape and size effects [37]. An electronic nose with powerful recognition ability toward gases is composed of a sensor array, which is constructed of several gas sensors. Each of them is a chromium titanium oxide (CTO) gas sensor combined with a catalysis layer on the respective type of zeolite. Many gas sensors based on the metal oxide semiconductor with Ptzeolite filter- $\mathrm{TiO}_{2}$ have been developed. These sensors exhibit a selective response to hydrocarbons in the presence of $\mathrm{CO}$ [38]. Gas sensors of Pd-doped $\mathrm{SnO}_{2}$ semiconductor covered with zeolitic films (MFI or LTA type) have been prepared and used for detecting different species (methane, propane, and ethanol) at different humidity levels. The dynamic responses presented by these sensors were compared with that of a reference sensor without the zeolitic layer. The results clearly indicated that a suitable zeolite layer strongly reduces the response of the sensor to paraffins. Thereby, the sensor selectivity towards alcohol increases, while the reference sensor could not discriminate between these molecules. This clearly shows the potential of zeolite-based sensors for achieving a higher selectivity/sensitivity in gas sensing applications [39].

A shape-selective resistive gas sensor using a natural STI type zeolite (Stilbite) was investigated for detecting polar molecules [40]. The electrical impedance of the zeolite single crystals decreases at $353 \mathrm{~K}$ in the presence of methanol, 2-propanol and 3-pentanol, but increases with increasing water and 
neo-pentanol vapor pressure. The interaction can be described by a Langmuir-type adsorption equation. Mobility effects due to stereo interactions in the zeolite channels have been used to interpret the conductivity response.

\subsection{Oxide/zeolite composites for $\mathrm{H}_{2}$ and $\mathrm{CO}$ sensors}

A Nano-tin dioxide/NaY zeolite composite material was prepared by impregnation of $\mathrm{SnCl}_{2}$ solution on $\mathrm{NaY}$ zeolite and subsequently calcination at 623-973 K. The nano-particles of $\mathrm{SnO}_{2}$ formed on the external surface of the zeolite. The composite material possesses the adsorption behavior of zeolite's open and perfect channel system, and presents a linear hydrogen-sensitivity demonstrated by conductivity measurements [41, 42]. Nano-particles of $\mathrm{SnO}_{2}$ have been embedded in the pores of FAU type zeolite (NaY) by chemical vapour deposition, ion exchange or impregnation followed by hydrolysis [43, 44]. These samples exhibited the most distinct decrease in the diffuse reflectance and highest rates for changes in the reflectance intensity during reduction with $\mathrm{CO}$. The optical changes are correlated to the number of oxygen vacancies in the particles, i.e. the deviations from the original $\mathrm{SnO}_{2}$ stoichiometry. In contrast to the reduction with $\mathrm{H}_{2}$, after reduction with $\mathrm{CO}$ all optical changes were completely reversible by addition of oxygen [44].

The reversible redox behavior of titanium dioxide clusters trapped within a zeolite in reducing and oxidizing atmospheres $\left(\mathrm{H}_{2}, \mathrm{CO}, \mathrm{O}_{2}\right)$ was studied by in situ diffuse reflectance UV/vis spectroscopy. Titanium oxide species, mononuclearly dispersed or as clusters with a particle size up to $2 \mathrm{~nm}$, have been stabilized in the pores of molecular sieves by chemical vapor deposition (CVD) or ion exchange from aqueous solutions and subsequent calcination. The zeolite matrix maintains good stability for the highly dispersed Ti (IV) oxide species. The response time of the hosted Ti (IV) oxide species for the optical registration of the presence of $\mathrm{H}_{2}$ in surrounding gas atmosphere decreased with the decreasing cluster size, and was the lowest for the mononuclear species with a highly distorted oxygen coordination sphere. In comparison to bulk $\mathrm{TiO}_{2}$, the response times of $\mathrm{Ti}$ (IV) oxide/zeolite composites were shortened by a factor of about 10 , and were comparable to the values found on solidstate electrolyte sensors. Also, the changes in the ratio of CO/air among the mixture can be easily monitored [45].

\subsection{Humidity sensors}

The novel zeolite guest/host material, LiCl/H-STI (stilbite) and $\mathrm{LiCl} / \mathrm{NaY}$ assembly were synthesized by a thermal dispersion method. The $\mathrm{LiCl}$ guest was highly dispersed into the channels of the host at the threshold assembly loading. The $\mathrm{LiCl} / \mathrm{H}$-STI material with threshold loading was found to possess optimum humidity-sensitive performance with a linear change of four orders of magnitude in electrical conductivity over the whole range of relative humidity. In addition, it also showed satisfactory reversibility and fast responses to environmental moisture changes [46-48]. The LiCl loading strongly influences the humidity-sensitive properties of $\mathrm{LiCl} / \mathrm{NaY}$ materials. The appropriate $\mathrm{LiCl}$ loading is $0.2 \mathrm{~g} / \mathrm{g}$ (weight ratio of $\mathrm{LiCl}$ to $\mathrm{NaY}$ ). Some disadvantages exist with the LiCl bulk material, including stability and durability issues at high humidity and at high temperature, 
contamination from dust or oil, etc., that have been overcome by use of the host-guest $\mathrm{LiCl} / \mathrm{NaY}$ composite material $[49,50]$.

Methylene blue (MB) encapsulated into the protonated MOR type (mordenite) zeolite (H-MOR) via ion exchange reaction was used for optical humidity sensing. The dye molecules are strongly retained in the channels of the zeolite and take part reversibly in the protonation/deprotonation reactions. The mechanism of the sensor is based on the protonation or deprotonation of the dye molecules which are associated with desorption or adsorption of water molecules by the zeolite, respectively. The spectral changes due to different humidity levels were probed by diffuse reflectance spectroscopy. The sensor presented a linear response range from 9 to $92 \%$ relative humidity with good stability and reversibility. The sensor operated at two bands, either of 650 or of $745 \mathrm{~nm}$, but a higher sensitivity of the measurement performance was exhibited at $650 \mathrm{~nm}$. The sensor provided relatively fast responses, and about 2 min of recovery time in the adsorption step and about 4 min in the desorption step for steam [51].

Films of LTA type zeolite on mass sensors (quartz crystal microbalances) were prepared and used for humidity microsensors. The zeolite's films are hydrophilic, thermally stable, and show reproducible responses. These films can be used effectively as humidity sensor materials for water vapor sensing purposes. High sensitivity, good reversibility, and long film life have been demonstrated at low steam concentrations [52]. For enhancing the sensitivity of the micron scale sensor devices, the ideal materials for loading are zeolites with high specific surface area and high selectivity towards water molecules. As an example, the experimental data of humidity sensing on a few single crystal zeolites attached to a cantilever sensor were presented [53].

\section{Conclusions}

The zeolite-based materials used in gas sensors have received great attention. The high and selective absorption properties of zeolites towards a specific gas greatly enhance the sensing selectivity for the gas. The compound or cluster sensing towards a gas assembled into the cages or channels of zeolites results in its high stability, and maximally elevate the sensing property of the materials. The application of composite materials partially composed of a zeolite, opens novel ways for choosing gas sensor materials as well. However, much more works remains to be done. Overall, we foresee that zeolites will become widely available materials for gas sensing in the next few years.

\section{Acknowledgements}

This work was supported by National Basic Research Program of China (2003CB615801) and the Science and Technology Foundation of Ministry of Construction (Projects 05-k2-33).

\section{References}

1. Breck, D.W. Zeolite Molecular Sieves, Chemistry and Use; Wiley: New York, USA, 1974.

2. Baerlocher, Ch.; Meier, W.M.; Olson, D.H. Atlas of Zeolite Framework Types. 5th ed.; Elsevier: London, 2001. 
3. Valdés Granda, M.; Pérez-Cordoves, A.I.; Díaz-García, M.E. Zeolites and zeolite-based materials in analytical chemistry. Trac-Trends Anal. Chem. 2006, 25, 24-30.

4. Coronas, J.; Santamaria, J. The use of zeolite films in small-scale and micro-scale applications. Chem. Eng. Sci. 2004, 59, 4879-4885.

5. Simon, U.; Franke, M.E. Electrical properties of nanoscaled host/guest compounds. Microporous Mesoporous Mat. 2000, 41, 1-36.

6. Meier, B.; Werner, T.; Klimant, I.; Wolfbeis, O.S. Novel oxygen sensor material based on a ruthenium bipyridyl complex encapsulated in zeolite-Y-dramatic differences in the efficiency of luminescence quenching by oxygen on going, from surface-adsorbed to zeolite-encapsulated fluorophores. Sensor. Actuator. B-Chem. 1995, 29, 240-245

7. Payra, P.; Dutta, P.K. Development of a dissolved oxygen sensor using tris(bipyridyl) ruthenium (II) complexes entrapped in highly siliceous zeolites. Microporous Mesoporous Mat. 2003, 64, 109-118.

8. Coutant, M.A.; Payra, P.; Dutta, P.K. Oxygen transport in zeolite Y measured by quenching of encapsulated tris(bipyridyl)ruthenium. Microporous Mesoporous Mat. 2003, 60, 79-90.

9. Lin, L.; Guthrie, J.T. Novel oxygen-enhanced membrane assemblies for biosensors. J. Membr. Sci. 2006, 278, 173-180.

10. Rauch, W.L.; Liu, M. Development of a selective gas sensor utilizing a perm-selective zeolite membrane. J. Mater. Sci. 2003, 38, 4307-4317.

11. Kaneyasu, K.; Otsuka, K.; Setoguchi, Y.; Sonoda, S.; Nakahara, T.; Aso, I.; Nakagaichi, N. A carbon dioxide gas sensor based on solid electrolyte for air quality control. Sensor. Actuator BChem. 2000, 66, 56-58.

12. Giannakopoulos, I.G.; Kouzoudis, D.; Grimes, C.A.; Nikolakis, V. Synthesis and characterization of a composite zeolite-metglas carbon dioxide sensor. Adv. Funct. Mater. 2005, 15, 1165-1170.

13. Fukui, K.; Nishida, S. CO gas sensor based on $\mathrm{Au}-\mathrm{La}_{2} \mathrm{O}_{3}$ added $\mathrm{SnO}_{2}$ ceramics with siliceous zeolite coat. Sensor. Actuator B-Chem. 1997, 45, 101-106.

14. Densakulprasert, N.; Wannatong, L.; Chotpattananont, D.; Hiamtup, P.; Sirivat, A.; Schwank, J. Electrical conductivity of polyaniline/zeolite composites and synergetic interaction with CO. Mater. Sci. Eng. B-Solid State Mater. Adv. Technol. 2005, 117, 276-282.

15. Chuapradit, C.; Wannatong, L.R.; Chotpattananont, D.; Hiamtup, P.; Sirivat, A.; Schwank, J. Polyaniline/zeolite LTA composites and electrical conductivity response towards CO. Polymer 2005, 46, 947-953.

16. Rodriguez-Gonzalez, L.; Franke, M.E.; Simon, U. Electrical detection of different amines with proton-conductive H-ZSM-5. Stud. Surf. Sci. Catal. 2005, 158, 2049-2056.

17. Franke, M.E.; Simon, U.; Moos, R.; Knezevic, A.; Muller, R.; Plog, C. Development and working principle of an ammonia gas sensor based on a refined model for solvate supported proton transport in zeolites. Phys. Chem. Chem. Phys. 2003, 5, 5195-5198.

18. Moos, R.; Muller, R.; Plog, C.; Knezevic, A.; Leye, H.; Irion, E.; Braun, T.; Marquardt, K.J.; Binder, K. Selective ammonia exhaust gas sensor for automotive applications. Sensor. Actuator. B-Chem. 2002, 83, 181-189. 
19. Simon, U.; Flesch, U.; Maunz, W.; Muller, R.; Plog, C. The effect of $\mathrm{NH}_{3}$ on the ionic conductivity of dehydrated zeolites $\mathrm{Na}$ beta and $\mathrm{H}$ beta. Microporous Mesoporous Mat. 1998, 21, 111-116.

20. Arakawa, T.; Kawabayashi, A.; Saga, T. Detection of butylamine by means of surface plasmon resonance. Sensor. Actuator. B-Chem. 2005, 108, 899-902.

21. Shul'ga, A.A.; Zuev, B.K.; Lontsov, V.V. Zeolite-containing sensitive coatings for surfaceacoustic-wave chemical gas sensors. J. Anal. Chem. 1999, 54, 449-454.

22. Sasaki, I.; Tsuchiya, H.; Nishioka, M.; Sadakata, M.; Okubo, T. Gas sensing with zeolite-coated quartz crystal microbalances-principal component analysis approach. Sensor. Actuator. B-Chem. 2002, 86, 26-33.

23. Osada, M.; Sasaki, I.; Nishioka, M.; Sadakata, M.; Okubo, T. Synthesis of a faujasite thin layer and its application for $\mathrm{SO}_{2}$ sensing at elevated temperatures. Microporous Mesoporous Mat. 1998, 23, 287-294.

24. Szabo, N.F.; Dutta, P.K. Strategies for total $\mathrm{NO}_{\mathrm{x}}$ measurement with minimal CO interference utilizing a microporous zeolitic catalytic filter. Sens. Actuator B-Chem. 2003, 88, 168-177.

25. Szabo, N.F.; Du, H.B.; Akbar, S.A.; Soliman, A.; Dutta, P.K. Microporous zeolite modified yttria stabilized zirconia (YSZ) sensors for nitric oxide (NO) determination in harsh environments. Sens. Actuator B-Chem. 2002, 82, 142-149.

26. Xie, H.F.; Yang, Q.D.; Sun, X.X.; Yu, T.; Zhou, J.; Huang, Y.P. Gas sensors based on nanosizedzeolite films to identify dimethylmethylphosphonate. Sens. Mater. 2005, 17, 21-28.

27. Huang, H.H.; Zhou, J.; Chen, S.Y.; Zeng, L.; Huang, Y.P. A highly sensitive QCM sensor coated with $\mathrm{Ag}^{+}-\mathrm{ZSM}-5$ film for medical diagnosis. Sensor. Actuator. B-Chem. 2004, 101, 316-321.

28. Mintova, S.; Bein, T. Nanosized zeolite films for vapor-sensing applications. Microporous Mesoporous Mat. 2001, 50, 159-166.

29. Zhou, J.; Li, P.; Zhang, S.; Long, Y.C.; Zhou, F.; Huang, Y.P.; Yang, P.Y.; Bao, M.H. Zeolitemodified microcantilever gas sensor for indoor air quality control. Sensor. Actuator. B-Chem. 2003, 94, 337-342.

30. Zhou, J.; Li, P.; Zhang, S.; Huang, Y.P.; Yang, P.Y.; Bao, M.H.; Ruan, G. Self-excited piezoelectric microcantilever for gas detection. Microelectron. Eng. 2003, 69, 37-46.

31. Grahn, M.; Wang, Z.; Lidstrom-Larsson, M.; Holmgren, A.; Hedlund, J.; Sterte, J. Silicalite-1 coated ATR elements as sensitive chemical sensor probes. Microporous Mesoporous Mat. 2005, 81, 357-363.

32. Xiao, H.; Zhang, L.; Dong, J.H.; Luo, M.; Lee, R.; Romero, V. Synthesis of MFI zeolite films on optical fibers for detection of chemical vapors. Opt. Lett. 2005, 30, 1270-1272.

33. Zhang, J.; Dong, J.H.; Luo, M.; Xiao, H.; Murad, S.; Normann, R.A. Zeolite-fiber integrated optical chemical sensors for detection of dissolved organics in water. Langmuir, 2005, 21, 86099612.

34. Dubbe, A.; Moos, R. Solid electrolyte hydrocarbon gas sensor using zeolite as the sensitive phase. Electrochem. Solid State Lett. 2006, 9, 31-34.

35. Plog, C.; Maunz, W.; Kurzweil, P; Obermeier, E.; Scheibe, C. Combustion gas sensitivity of zeolite layers on thin-film capacitors. Sensor. Actuator. B-Chem. 1995, 25, 403-406. 
36. Sahner, K.; Moos, R.; Matam, M.; Tunney, J.J.; Post, M. Hydrocarbon sensing with thick and thin film p-type conducting perovskite materials. Sensor. Actuator. B-Chem. 2005, 108, 102-112.

37. Mann, D.P.; Paraskeva, T.; Pratt, K.F.E.; Parkin, I.P.; Williams, D.E. Metal oxide semiconductor gas sensors utilizing a Cr-zeolite catalytic layer for improved selectivity. Meas. Sci. Technol. 2005, 16, 1193-1200.

38. Trimboli, J.; Dutta, P.K. Oxidation chemistry and electrical activity of Pt on titania: development of a novel zeolite-filter hydrocarbon sensor. Sensor. Actuator. B-Chem. 2004, 102, 132-141.

39. Vilaseca, M.; Coronas, J.; Cirera, A.; Cornet, A.; Morante, J.R.; Santamaria, J. Use of zeolite films to improve the selectivity of reactive gas sensors. Catal. Today, 2003, 82, 179-185.

40. Schaf, O.; Wernert, V.; Ghobarkar, H.; Knauth, P. Microporous Stilbite single crystals for alcohol sensing. J. Electroceram. 2006, 16, 93-98.

41. Xu, X.W.; Wang, J.; Long, Y.C. Nano-tin dioxide/NaY zeolite composite material: Preparation, morphology, adsorption and hydrogen sensitivity. Microporous Mesoporous Mat. 2005, 83, 6066.

42. Xu, X.W.; Wang, J.; Long, Y.C. Formation of $\mathrm{SnO}_{2}$ nanoparticles on external surface of NaY zeolite. Chin. J. Chem. 2005, 23, 359-361.

43. Schwenn, H.J.; Wark, M.; SchulzEkloff, G.; Wiggers, H.; Simon, U. Electrical and optical properties of zeolite Y supported $\mathrm{SnO}_{2}$ nanoparticles. Colloid Polym. Sci. 1997, 275, 91-95.

44. Warnken, M.; Lazar, K.; Wark, M. Redox behaviour of $\mathrm{SnO}_{2}$ nanoparticles encapsulated in the pores of zeolites towards reductive gas atmospheres studied by in situ diffuse reflectance UV/Vis and Mossbauer spectroscopy. Phys. Chem. Chem. Phys. 2001, 3, 1870-1876.

45. Grubert, G.; Stockenhuber, M.; Tkachenko, O.P.; Wark, M. Titanium oxide species in molecular sieves: Materials for the optical sensing of reductive gas atmospheres. Chem. Mat. 2002, 14, 2458-2466.

46. Zou, J.; He, H.Y.; Dong, J.P.; Long, Y.C. A guest/host material of LiCl/H-STI (stilbite) zeolite assembly: preparation, characterization and humidity-sensitive properties. J. Mater. Chem. 2004, 14, 2405-2411.

47. Zou, J.; He, H.Y.; Dong, J.P.; Long, Y.C. A novel LiCl/H-STI zeolite guest/host assembly material with superior humidity sensitivity: Fabrication and characterization. Chem. Lett. 2001, 8, 810-811.

48. Zou, J.; Luo, Z.L.; Jiang, Z.Y.; Long, Y.C. Studies on CXN natural zeolite IV. Research on the humidity-sensitive property of the novel LiCl/H STI guest/host material. Acta Chim. Sin. 2001, 59, 862-866.

49. Li, N.; Li, X.T.; Zhang, T.; Qiu, S.L.; Zhu, G.S.; Zheng, W.T.; Yu, W.X. Host-guest composite materials of LiCl/NaY with wide range of humidity sensitivity. Mater. Lett. 2004, 58, 1535-1539.

50. Li, X.T.; Shao, C.L.; Ding, H.; Zhang, T.; Li, N.; Qiu, S.L.; Xiao, F.S. Preparation and humidity sensitive property of $\mathrm{LiCl} / \mathrm{NaY}$ composite materials. Chem. J. Chin. Univ.-Chin. 2000, 21, 11671170 .

51. Zanjanchi, M.A.; Sohrabnezhad, S. Evaluation of methylene blue incorporated in zeolite for construction of an optical humidity sensor. Sensor. Actuator. B-Chem. 2005, 105, 502-507.

52. Mintova, S.; Mo, S.Y.; Bein, T. Humidity sensing with ultrathin LTA-type molecular sieve films grown on piezoelectric devices. Chem. Mat. 2001, 13, 901-905. 
53. Scandella, L.; Binder, G.; Mezzacasa, T.; Gobrecht, J.; Berger, R.; Lang, H.P.; Gerber, C.; Gimzewski, J.K.; Koegler, J.H.; Jansen, J.C. Combination of single crystal zeolites and microfabrication: Two applications towards zeolite nanodevices. Microporous Mesoporous Mat. 1998, 21, 403-409.

(C) 2006 by MDPI (http://www.mdpi.org). Reproduction is permitted for noncommercial purposes. 